\title{
O DESCOMPASSO ENTRE A LEGISLAÇÃO QUE REGULA A GESTÃO DEMOCRÁTICA DA ESCOLA E O FUNCIONAMENTO DOS CONSELHOS DE ESCOLA
}

\section{THE DISCREPANCY BETWEEN THE LEGISLATION GOVERNING THE DEMOCRATIC MANAGEMENT OF THE SCHOOL AND THE OPERATION OF SCHOOL BOARDS}

Jefferson Alves da ROCHA ${ }^{1}$ Áurea de Carvalho COSTA ${ }^{2}$

RESUMO: Das análises sobre a gestão democrática, o presente artigo apresenta o descompasso entre o proposto na letra da lei e o implantado no cotidiano dos conselhos escolares. Segue-se da pesquisa empírica que a gestão escolar permanece centralizada na figura do diretor. Apesar do avanço sobre a instituição dos conselhos, a dicotomização entre os quadros profissionais da escola e os pais de alunos tem revelado a dinâmica de funcionamento destes no cotidiano escolar. Apreendemos por meio da legislação, da observação e das atas, como se dá a participação social dos membros colegiados na gestão escolar do Ensino Fundamental de Rio Claro/SP.

PALAVRAS-CHAVE: Gestão democrática. Participação social. Conselhos de escola.

ABSTRACT: From an overall perspective of democratic management, this article presents the mismatch between what is proposed in the letter of the law and what is routinely implemented in general school boards. It was concluded that school management is still focused on the principal figure. Despite advancements in school boards, dichotomization between the school staff and the students' parents has shown the working dynamics of the boards in the daily schools. Through legislation, observation and the minutes, we could see how collegiate members' social participation happens when it comes to managing primary schools in the city of Rio Claro, SP.

KEYWORDS: Democratic management. Social participation. School general boards.

\section{Introdução}

No atual contexto político brasileiro e internacional, de intensas discussões e embates envolvendo a questão da democracia, especialmente no que tange à crise das representações políticas na forma democrática, torna-se cada vez mais necessário refletir sobre a própria democracia representativa, sua potencialidade e seus limites no âmbito do modo de produção capitalista. Para o presente trabalho, elegemos o

\footnotetext{
${ }^{1}$ Mestre em Educação, pela Universidade Estadual Paulista “Júlio de Mesquita Filho” Campus de Rio Claro.

2 Professora Doutora, do Instituto de Biociências, da Universidade Estadual "Júlio de Mesquita Filho" Campus de Rio Claro.
} 
pressuposto de que esse modelo gestionário da democracia representativa se concretiza desde as instâncias do poder que efetivamente governam o país, por meio de uma sociedade política Gramsci (1980), ou seja, de um conjunto de representantes eleitos pelo sufrágio universal para ocupar o Legislativo o Executivo. Estes, além de também indicarem quadros para o Judiciário, instituem um modelo gestionário que orienta a gestão de todas as instituições sociais, dentre elas a escola pública.

Assim, numa perspectiva mais geral, buscamos colaborar na reflexão sobre como o modelo de gestão democrática representativa se efetiva no chamado "chão de escola", compreendendo que desde o momento da reabertura política no Brasil, em 1984, a gestão democrática tem sido repensada pelos sucessivos governos, bem como amplamente criticados por movimentos sociais ligados à classe trabalhadora, o que nos levou a indagar como tem se efetivado concretamente a participação social e a cidadania, tendo em vista o desenvolvimento de um modelo gestionário de organização democrática sob a forma representativa que emana do Estado democrático de direito neoliberal.

A partir desta indagação, propomos a hipótese de que existe contradição, pois, se, por um lado, a garantia da gestão democrática da escola na forma da lei foi uma vitória dos movimentos sociais em meio ao processo de transição política, na década de 1980, de um regime militar-autoritário para a democracia, no momento de sua consolidação na Lei de Diretrizes e Bases da Educação Nacional, em 1996, o país era administrado a partir de um novo modelo de gestão, de marca neoliberal, decorrente da reforma do Estado na década de 1990 e que traz uma concepção de cidadania e de participação social na qualidade de votante e usuário de serviços do Estado e da sociedade civil.

Assim, nos questionamos se tal contradição penetrou às escolas e influenciou de alguma maneira sua gestão democrática, tendo em vista a orientação das políticas educacionais sobre a forma peculiar de funcionamento dos conselhos de escola, bem como a oposição entre gestores e professores, por um lado, e professores e pais, por outro, no que se refere a atuação destes nos órgãos colegiados: a partir da Lei Complementar $n^{\circ} 444 / 85$ e a ratificação na LDBEN no 9394/96, a hipótese sobre a dicotomização entre os quadros de funcionários do Estado de modo que os primeiros figuram como oferecedores de serviços e os últimos, como usuários.

Justificamos nossa hipótese a partir da observação em algumas escolas de rede de Ensino Fundamental de Rio Claro/SP que a paridade sobre as decisões educacionais, 
na forma da lei, constitui-se no fato de metade ser composta por professores, gestores e funcionários e outra metade, por pais e alunos. Entretanto, pontuamos o estabelecimento de uma dicotomização entre os que são "de dentro" e os que são "de fora" dos quadros do Estado e a consequência disso sobre as deliberações dos conselhos de escola.

Diante dessa constatação, indagamo-nos: esta dicotomização decorreria da concepção de cidadão consumidor, em que os "de fora" teriam, antes, uma função de fiscalização do que de efetiva participação nas deliberações escolares?

Para nos aproximarmos desta questão dedicamo-nos a análise do princípio da gestão democrática nas políticas educacionais da rede municipal de Rio Claro/SP, a fim de apontar as contradições que envolvem a participação social dos diferentes segmentos da escola na organização do trabalho nesta instituição, assim como as orientações da legislação educacional para a gestão democrática por meio dos conselhos nas unidades escolares.

Nossas análises não poderiam prescindir do recorte de classe porque, embora a escola pública, gratuita e obrigatória, seja um direito universal para qualquer cidadão, independente de classe social, hoje é frequentada predominantemente pelos filhos de trabalhadores, os quais têm nela sua principal chance de estudar, formar-se e ter contato com o saber sistematizado, tornando-se dependente do Estado para obtenção da educação formal. Assim, a classe trabalhadora ocupa a instituição escolar, necessariamente, enquanto que a classe detentora dos meios de produção pode procurar alternativas de formação escolar em diferentes perspectivas e níveis de qualidade e recursos pedagógicos disponíveis na rede privada de ensino.

E, ao mesmo tempo em que são estabelecidas políticas de Estado para a democratização e a ampliação dos direitos de participação social e de cidadania para a classe trabalhadora, ocorre o processo de descentralização das tarefas administrativas por parte do Estado no que se refere à redemocratização da gestão das instâncias sociais, em especial a escola pública. Entretanto, sem necessariamente ocorrer a descentralização do poder, pois, o financiamento do sistema, a elaboração do corpus jurídico que a regula, bem como os instrumentos de avaliação dos indivíduos e do sistema escolar permanecem sob o controle do poder central (COSTA, 2010).

A hipótese que nos propomos a desenvolver é, desde a inclusão da gestão democrática no rol dos princípios da educação, na Constituição Federal de 1988, até sua ratificação na Lei de Diretrizes e Bases da Educação Nacional de 1996, o acentuado descompasso entre o proposto na letra da lei e o implantado no cotidiano dos conselhos 
de escola, nos estabelecimentos de ensino públicos. Tendo em vista ainda, até o momento, que a gestão das escolas permanece centralizada na figura dos gestores, os quais concentram as tarefas burocráticas e as escolhas pedagógicas para a escola.

Apesar do indubitável avanço que representou a instituição dos conselhos como órgãos máximos deliberativos nas unidades escolares, o diretor de escola, por lei, é o presidente nato, representando $5 \%$ de gestores nos conselhos, além de $5 \%$ de funcionários, $40 \%$ de professores, $25 \%$ de pais e $25 \%$ de alunos - cujos direitos políticos limitados conforme a faixa etária (SÃO PAULO, 1985).

A partir desta primeira observação da lei, formulamos a hipótese supracitada e investigamos como se opera a participação qualitativa, nas funções deliberativa, legislativa e consultiva no cotidiano dos conselhos escolares, a fim de identificar a existência de tal descompasso e, em caso positivo, se ele teria relação com a concepção neoliberal de cidadão-cliente. O principal indicativo deste descompasso seria decorrente do estabelecimento da LDBEN de 1996, sobretudo de orientações para a gestão democrática nos sistemas de ensino, cuja aplicação tem sido mais formal do que real (BRASIL, 1996).

Indagamo-nos, ainda, se os Conselhos de Escola reproduzem a dinâmica do Estado Ampliado (GRAMCI, 1980), ao atuar como instância máxima deliberadora na unidade escolar - sociedade política - ao mesmo tempo em que é o órgão representativo dos diferentes setores da comunidade escolar, quais sejam, os professores, os alunos, os pais e os gestores, constituindo-se assim, como representação da sociedade civil.

Para nossa pesquisa empírica selecionamos, a partir de um conjunto de 25 escolas totais, uma amostra de nove escolas públicas municipais do Ensino Fundamental de ciclo I - do $1^{\circ}$ ao $5^{\circ}$ ano na rede municipal de Rio Claro, para a coleta de dados sobre o funcionamento da gestão democrática nas unidades escolares. Por meio da análise de atas e das observações nas reuniões colegiadas, a partir das considerações de Paro (1991; 1996; 2005) colaboramos na elucidação sobre o cotidiano destes conselhos, se efetivam ou não a gestão democrática e como se dão as atuações dos diferentes setores da comunidade escolar.

Segundo Silveira e Adrião (2009) os órgãos colegiados podem ser entendidos como órgãos de construção de consensos, de negociação de interesses dos diferentes setores e essa é a sua finalidade desde o ponto de vista formal, jurídico, porém, será que isso se efetiva no cotidiano? Propomos a problematização de que este mecanismo, mesmo sendo relevante para a democratização das relações entre os segmentos na 
escola, ainda guarda contradições, devido ao fato de se situar no interior de uma escola capitalista, uma instituição pública que reproduz no seu interior as relações de poder de um modelo de Estado neoliberal, que institui práticas autoritárias cujos sujeitos passam a ser os próprios membros do colegiado.

\begin{abstract}
A administração escolar torna-se cada vez mais identificada com as orientações administrativo-gerenciais, em especial aquelas voltadas para a captação de recursos financeiros e para a melhoria da performance dos alunos nos testes sistêmicos de aferição do desempenho escolar. A lógica gerencial que associa recursos financeiros a estratégias de melhoria de desempenho escolar tende a subjugar as decisões políticas e consensuais aos parâmetros técnicos e administrativos, o que, na pratica fortalece a centralização do poder e a autoridade técnica como base para a tomada de decisões e para a organização escolar (SILVA; ALVES, 2012, p. 678).
\end{abstract}

E, para apreendermos tais contradições envolvendo a gestão democrática no cotidiano escolar, coletamos dados durante a participação em algumas reuniões do conselho no primeiro semestre de 2016 na qualidade de ouvinte, bem como na análise dos documentos oficiais das reuniões do órgão colegiado que tivemos acesso - as atas para a apreciação dos encaminhamentos dentre outros elementos que contribuíam para a elucidação das relações de poder durante o cotidiano do funcionamento desses conselhos. Nesta exposição, dividimos o artigo em introdução aos conceitos que fundamentaram nossa discussão, apreciação da legislação municipal de Rio Claro sobre o tema e apresentação da análise de atas e das notas de campo, obtidas da participação nas reuniões.

\title{
Descaminhos da democracia na escola
}

Uma discussão sobre a gestão democrática da escola não pode prescindir a apresentação da concepção de participação social e a cidadania que fundamenta a política pública na escola. Desse modo são apresentados, na letra da lei, os conselhos de escola como órgãos máximos deliberativos na unidade escolar, portanto, locus privilegiado de produção de consensos com relação à organização do trabalho escolar, as decisões curriculares, a regulação entre os segmentos da escola e as decisões pedagógicas, tais como as decisões sobre a parte diversificada do currículo, as medidas de flexibilização da jornada escolar e outras medidas previstas na legislação educacional de 1996. 
Entretanto, quando se estabeleceu tal gestão mais participativa na LDB, concomitante à reforma do Estado por meio do Ministério da Reforma do Estado, instalado em 1994, isso se deu a partir de uma determinada concepção de participação que visava à racionalização do trabalho na escola. A partir de critérios, tais como a eficiência e a eficácia no que tange a administração dos serviços públicos, estabeleceuse o grande objetivo da Reforma de todo o aparelho de estado, do qual a instituição escolar não poderia ter sido excluída, por ser, ela mesma, um braço do Estado (COSTA, 2013).

Segundo o entendimento de Bresser Pereira (1997) a reforma do Estado tinha como objetivo, proporcionar uma maior governabilidade ao torná-lo mais democrático, o que só poderia ser obtido por meio da instituição do modelo de Estado Mínimo como política oficial, pela sua peculiaridade de legislar sobre os aspectos mais gerais, deixando aos cidadãos e instituições da sociedade civil a liberdade para deliberarem sobre questões específicas. De acordo com Hayek (2010) tendo em vista a incapacidade estrutural do Estado de administrar todas as vontades particulares da sociedade civil, por isso, sendo edificado um novo modelo de Estado a partir da ideia de que deveria haver uma “[...] conceituação das novas instituições que definirão o novo Estado que está surgindo [...] a 'lógica do leque de mecanismos e controle' que fundamenta a escolha de instituições e formas de atuação do Estado [...]” (BRESSER PEREIRA, 1997, p. 7).

Conforme Faleiros (1987), tal reforma se refere a uma forma de gestão estatal da força de trabalho, na medida em que são articuladas as proposições da classe trabalhadora com as formas de reprodução social exigidas pela valorização do capital, apresentadas à sociedade como promotora da justiça social equitativa e de garantia de uma estabilidade política e de um desenvolvimento econômico, ao mesmo tempo. Assim, as diversas reformas sociais visam à criação de mecanismos e de instâncias com conteúdos democráticos proporcionando a participação direta da classe trabalhadora nos processos decisórios de acordo com a nova proposta de organização administrativa (ADRIÃO; CAMARGO, 2001).

Contudo, os direitos de participação social e de cidadania na atual conjuntura neoliberal passam a ser ressignificados de modo que o processo da descentralização administrativa do Estado implica numa nova forma de atuação política da classe trabalhadora sobre os processos decisórios. E qual seria o elemento novo? De acordo com Ludwig (2009), trata-se de estimular a ação no interior dos grupos com vistas à solução dos problemas escolares cotidianos. 
A participação social tem um sentido cada vez mais colaborativo e mais dependente das decisões do poder central, uma vez que ocorre, na verdade, é a desconcentração de tarefas e a concentração do poder deliberativo, legislativo e avaliador nas instâncias centrais do poder. Nesse sentido são balizadas a atuação dos conselhos na unidade escolar, os quais se organizam fazendo escolhas, porém, sempre direcionadas para dar respostas às demandas do poder centralizado, na medida as unidades escolares, os professores e os alunos são constantemente avaliados por instituições externas a eles (SILVA; ALVES, 2012).

A ambiguidade entre uma proclamada gestão democrática descentralizada, em que o conselho se torna o órgão máximo de deliberação na escola e a real dependência da legislação, do financiamento e da avaliação que fogem ao controle do conselho escolar acabam gerando uma situação no qual a liberdade se restringe à escolha de tarefas necessárias ao cumprimento de metas preestabelecidas e com os recursos previstos.

Então, a dinâmica de funcionamento da gestão democrática tem ocorrido não sem contradições no interior da escola, uma vez que todas as políticas públicas não se encontram livre das disputas e interesses entre o Estado burguês e classe trabalhadora, no que se refere à organização e o controle do trabalho escolar. Desse modo, a especificidade da gestão democrática neoliberal pressupõe uma concepção de participação cidadã para a classe trabalhadora, na condição de colaborador e consumidor de serviços educacionais no processo de organização da escola pública, antes, numa perspectiva de adaptação da escola à sociedade capitalista, regida pela estratégia político econômica neoliberal.

A partir do pressuposto do antagonismo de classes e do desenvolvimento das relações sociais de produção (MARX, 1996; 2010) pontuamos que se tem produzido o consenso de que haveria uma igualdade entre os seres, mas oculta que esta é apenas jurídica não se traduzindo numa igualdade real, no que se refere à participação no usufruto da riqueza socialmente produzida, nem mesmo na garantia de uma igualdade na participação social e política. Por isso, no âmbito do neoliberalismo, se cunhou o conceito equidade e que diz respeito ao acordo entre os diferentes, na impossibilidade total de se produzir qualquer forma de igualdade (HAYEK, 2010). Isso tem total sentido neste modo de produção, na medida em que a relação dos proprietários dos meios de produção com os proprietários apenas da força de trabalho é marcada pela exploração. Esta é a principal barreira para uma democratização da gestão em que haja, de fato, compartilhamento de poder, pois, 
A trajetória política trilhada pela sociedade brasileira prescinde de um profundo desenvolvimento democrático, que ainda está para ser construído culturalmente como valor universal e, par que haja uma reconstrução prospectiva da gestão democrática, na perspectiva da socialização do poder, será necessária uma inversão desses valores que vêm se fortalecendo a partir dos parâmetros neoliberais (SILVA, ALVES, 2012, p. 679).

\section{Os avanços na regulamentação dos conselhos de escola}

O aparato legal que orientou a implantação dos Conselhos de Escola nas políticas locais constitui-se de três legislações municipais: a Lei $\mathrm{n}^{\circ} 2.081$, de 31 de outubro de 1986, que dispõe sobre o Estatuto do Magistério Público Municipal, promulgada quase um ano após a publicação da Lei Complementar Estadual $\mathrm{n}^{\mathrm{o}}$ 444/1985; a Lei $n^{\circ} 3.031$, de 22 de março de 1999, que atualiza a Lei Municipal 2.081/86 sobre os Conselhos de Escola; e a Lei $n^{\circ}$ 4.247, de 30 de setembro de 2011, que regulamenta os órgãos colegiados nos estabelecimentos de ensino da rede municipal de Rio Claro.

A regulamentação jurídica sobre os conselhos nas escolas de Ensino Fundamental fora prevista na Lei Municipal $\mathrm{n}^{\circ} 2.081$, no Art. 123, definindo-os como órgão deliberativo e consultivo (RIO CLARO, 1986, p. 44). Entretanto, até 1986 não estavam organizados os estabelecimentos de Ensino Fundamental do município e nas escolas de educação infantil o conselho não existia, por isso, naquele momento tratavase de uma previsão e não da regulação de algo já existente no cotidiano da rede municipal em estudo.

Durante o governo de Mário Covas, no período de 1995 a 1998, a secretária da educação Teresa Roserley Neubauer da Silva empreendeu esforços para a descentralização e desconcentração dos recursos, além das mudanças no padrão de gestão, que influenciou na municipalização do ensino em Rio Claro, no ano de 1997 (Cf. SILVEIRA; ADRIÃO, 2009). O processo de implantação dos conselhos deu-se como consequência da introdução do ensino fundamental na rede municipal e da descentralização do regimento escolar em 1998. Então, cada escola adquiriu a prerrogativa de elaborar seu próprio Regimento Escolar, em substituição ao antigo Regimento da secretaria da educação previsto para todas as unidades, colaborando para 
a ampliação da autonomia pedagógica assegurada na Lei $\mathrm{n}^{\circ}$ 9394/96 (SILVEIRA; ADRIÃO, 2009).

A partir de uma comparação entre o Artigo 95 da legislação complementar estadual de 1985 e os Artigos 123 a 127 da legislação municipal de 1986, constatamos que este último é mais centralizador de poder nas mãos dos quadros profissionais da escola, rompendo com a paridade entre comunidade escolar e quadros profissionais: enquanto o estatuto estadual estabelece um conselho formado por $40 \%$ de docentes, $5 \%$ de especialistas em educação, $5 \%$ de funcionários, $25 \%$ de pais e $25 \%$ de alunos, no estatuto municipal o conselho era previsto uma composição majoritariamente por educadores e gestores. Essa estrutura assemelha-se, antes, a um comitê assessor da escola do que a um órgão de gestão colegiada: o coordenador, um professor, o assistente de diretor, o diretor e somente dois representantes dos pais, ademais, sem a participação de alunos e de outros quadros de funcionários da escola.

A escolha dos representantes se restringe aos professores e aos pais, os quais deveriam ser escolhidos por $2 / 3$ dos membros da escola. A três vagas de gestores eram preenchidas de modo preestabelecido: o coordenador, o assistente de diretor e o diretor, sendo este último o presidente nato.

A Lei Municipal de 1986 previa uma atuação mais na perspectiva consultiva e de assessoria do que de deliberação, na medida em que suas atribuições eram de fiscalizar o atendimento às normas, propor medidas de aperfeiçoamento do ensino, planejar de atividades extracurriculares, elaborar o calendário escolar, assim como articular a escola e a comunidade e solucionar problemas dos alunos (RIO CLARO, 1986, p. 45).

Demorou uma década para a atualização das normas de funcionamento dos conselhos escolares no Estatuto do Magistério Municipal. A partir da Lei Municipal $\mathrm{n}^{\circ}$ 3.031, de 25 de março de 1999 - expresso no Art. 123 - é que se fortaleceu a função mediadora dos conselhos entre a realidade de cada unidade escolar e a do município, ampliando o poder decisório referente às questões pedagógicas de modo a [...] ajustar as diretrizes e metas estabelecidas pela Secretaria Municipal de Educação em conjunto com o Conselho Municipal de Educação à realidade de Unidade Escolar [...] (RIO CLARO, 1999, p. 1), avançando em outros aspectos: no Art. 124, no estabelecimento das orientações sobre a composição paritária entre quadros profissionais da escola e os quadros da comunidade escolar e local e no Art. 125; na regulamentação do processo de escolha das representações do órgão colegiado, mediante processo eletivo direto entre 
seus pares; no Art. 126, na proporcionalidade de participantes do colegiado pela quantidade maior de turmas no período da escola (RIO CLARO, 1999).

Com essas atualizações na lei municipal de 1999 abre-se um espaço maior para a participação política dos representantes da comunidade local desde a legislação, tendo em vista à democratização das relações políticas no interior da escola e a constituição de uma equipe maior de trabalho para que possa discutir mais as decisões, assim como fomentar a proposição de medidas que realmente interessem ao grupo que eles representam (Silveira; Adrião, 2009). Permitiu que as deliberações fossem mais coletivas no interior da escola, em detrimento de uma deliberação centralizada na figura da equipe gestora, conforme se observava na Lei municipal n. ${ }^{\circ}$ 2.081/86. A legislação de 1999 avança até mesmo em relação ao artigo 95 da Lei Complementar Estadual $n^{\circ}$ 444/85, na qual não está prevista a presença de membros representantes da comunidade (SÃO PAULO, 1985).

Enquanto que na legislação de 1986, a escolha das representações era condicionada a uma reunião que exigia um quórum mínimo de $2 / 3$ dos membros da escola, que as decisões fossem estabelecidas por meio de uma maioria simples de voto e que a escolha dos representantes se restringia aos membros da escola, permitindo uma participação esvaziada nas deliberações do órgão colegiado (RIO CLARO, 1986), na legislação municipal de 1999 a eleição da composição colegiada prevê a realização de uma assembleia geral e, para as reuniões ordinárias ou não o quórum mínimo de 1/3 das representações (RIO CLARO, 1999). Contudo, o processo de implantação de conselhos na rede de Ensino Fundamental se deu a partir de 2000, quando se instituiu que os primeiros conselheiros de cada escola deveriam apresentar candidaturas em assembleias gerais em cada unidade escolar e serem escolhidos pelo voto direto (RIO CLARO, 1999).

Vale lembrar que, tendo em vista a preencher a lacuna de uma regulamentação específica para os conselhos de escola é promulgada a Lei ${ }^{\circ} 4.247$, de 30 de setembro de 2011, o que denota um atraso considerável quanto à institucionalização da participação colegiada para o âmbito escolar, previsto como política pública na forma da lei ainda na década de 1980. Esta lei amplia os poderes dos conselhos escolares, na medida em que suas atribuições ultrapassam o âmbito pedagógico e abrangem toda a organização do trabalho escolar, bem como sua relação com a comunidade: “[...] estabelecendo no âmbito da escola, diretrizes e critérios gerais relativos à sua ação, organização, funcionamento e relacionamento com a comunidade, compatíveis com as 
orientações da Política Educacional da Secretaria Municipal da Educação [...]" (RIO CLARO, 2011, p. 1).

O Conselho ganha a função de garantir a democracia participativa desde as unidades escolares, por meio de relações paritárias e sendo difundidas uma cultura de compartilhamento de responsabilidades sobre a escola entre gestores e professores, pais e os próprios alunos. É importante destacar que conselho escolar ganha, agora, poderes legislativos, o que é inédito em relação às legislações anteriores, bem como a tarefa de circulação das decisões por meio de um sistema de difusão de informações e de organização dos coletivos em assembleias, o que permite um maior controle social da gestão, por meio da prestação de contas. Estabelece uma concepção de comunidade escolar que concorre para o protagonismo de todos os participantes da escola, qual seja, “[...] o conjunto dos pais ou responsáveis pelos alunos e alunos maiores de 18 anos, regularmente matriculados nas unidades escolares municipais, inclusive os da Educação de Jovens e Adultos" (RIO CLARO, 2011, p. 3).

O nível de sofisticação do documento chega aos níveis da definição dos segmentos que tem direito a voz e voto, detalhando os sujeitos que participam da escola com direito à voz somente nas assembleias - os alunos menores de 18 anos, os professores temporários e demais servidores das secretarias municipais de educação, assim como os representantes de entidades conveniadas e membros de outras instituições de ensino, sinalizando que o debate deve ser o mais amplo possível.

É garantido um colegiado realmente representativo ao serem ratificados os critérios previstos na legislação de 1999: quanto à proporcionalidade, escolhendo o turno com o maior número de turmas como referência; quanto à legitimidade das reuniões, a convocação de assembleias, a ser conduzida pelo presidente ou vicepresidente do conselho e a partir de um quórum mínimo de $30 \%$ na primeira chamada e de $10 \%$ na segunda chamada; quanto à representatividade política, eleita por meio de voto secreto, de forma bienal e irrevogável. Ademais, sendo a presidência do conselho eleita de forma indireta, dando entre os membros a chance elegível para o cargo.

Do ponto de vista legal, todas as condições para a atuação de um conselho de escola democrático, representativo e participativo estão satisfeitas para que este órgão deliberativo atue efetivamente nas unidades escolares concretizando a gestão democrática. Entretanto, tal legislação não é suficiente para a instauração de uma cultura de gestão democrática no cotidiano escolar, conforme se constata nas análises das atas das reuniões colegiadas nas escolas. A explicação deste problema se dá a partir 
da eleição da presidência do conselho escolar e na concepção de cidadão cliente neoliberal que é impregnada nas relações entre os quadros profissionais da escola e a comunidade escolar, de modo que os últimos passam a atuar enquanto financiadores dos serviços educacionais, sob a responsabilidade dos quadros profissionais, o que denota uma dicotomização entre os segmentos representativos no interior dos conselhos.

Em decorrência do conceito de conselho estabelecido na lei de 1999 como locus não de deliberações de políticas mais gerais para a unidade escolar, mas “[...] um centro permanente de debate e de articulação entre os vários setores da escola, tendo em vista o atendimento das necessidades comuns e a solução dos conflitos que possam interferir no funcionamento do estabelecimento de ensino e nos problemas administrativos, financeiros e pedagógicos [...] (RIO CLARO, 2011, p. 1, grifos nossos), discutimos as contradições que envolvem o funcionamento dos conselhos de escola.

\section{Na prática, a teoria é outra: o cotidiano da gestão colegiada da escola}

Do ponto de vista prático, a questão do financiamento e as condições de trabalho se tornam os obstáculos imediatos ao avanço da autonomia da escola, por mais que a legislação crie dispositivos para a realização desse fim. Segundo Silva e Alves (2012) as condições objetivas de precarização do trabalho e a degradação da estrutura física das escolas, somada a uma limitação dos recursos financeiros da escola tendem a comprometer as relações efetivamente democráticas, tendo em vista a ausência de acompanhamento da parte pedagógica em razão da acentuada pressão para o fortalecimento de uma autonomia financeira e administrativa no cotidiano escolar pelas políticas de Estado.

A partir disso pontuamos as contradições envolvendo a dinâmica de funcionamento dos órgãos colegiados com base em dois apontamentos: 1) as proposições de pautas e as deliberações realizadas de modo centralizado por parte da direção escolar; 2) as ações do órgão colegiado envolvendo o financiamento e a manutenção do ambiente escolar.

Quanto ao primeiro apontamento, das observações nas reuniões colegiadas nas escolas, constatamos que as apresentações das pautas e as deliberações eram sempre centralizadas na figura da direção escolar, dos coordenadores e vice-diretores, não 
havendo espaço para os pais de alunos ou responsáveis nas proposições de pautas ou mesmo nas deliberações.

Identificamos que a participação nas decisões e em cada reunião do conselho se dava de forma hierarquizada, de modo que quem propõe e decide, na verdade, eram os gestores. Aos pais de alunos ou responsáveis reservada as funções de avalistas ou de fiscais sobre as decisões, uma vez que não envolvia nas reuniões a cultura de se colocar em votação cada deliberação, encaminhamento ou mesmo a proposição de pauta para a próxima reunião.

Isso foi evidenciado quando participamos das reuniões e analisamos as atas das nove escolas municipais pesquisadas, sendo constatado que, apesar de uma composição sob a forma paritária em seis delas, em todas as escolas não observamos qualquer atuação dos membros da comunidade local eleitos para o cargo de presidente do conselho escolar.na centralização das decisões.

Ainda que a legislação municipal traga o entendimento de que para o cargo da presidência do conselho, com exceção da direção escolar, todos possam assumir (RIO CLARO, 2011), vimos que em todas as nove escolas analisadas é o diretor quem assume todas as diligências do órgão colegiado, desde as convocações para as reuniões, até deliberações financeiras. Ademais, quando não assumida por este, fica à cargo de outro membro pertencente ao segmento escolar (vice direção, coordenador ou professor), nunca envolvendo a atuação dos pais de alunos ou responsáveis, ainda que estes ocupem os cargos de presidência do conselho nas escolas. $\mathrm{O}$ que evidenciamos não foram as ausências dos presidentes às reuniões, mas, a centralização das decisões sob a responsabilidade do diretor ou de quadros profissionais da escola, sendo constatado em seis escolas analisadas que o membro da comunidade local eleito para compor a presidência se tratava de uma representação política do ponto de vista formal apenas. Nas três escolas em que a composição colegiada não se deu de forma paritária, isso se evidenciava ainda mais pelo fato de que a quantidade representantes da comunidade era menor em relação aos representantes dos quadros profissionais da escola - pelo menos, tendo dois membros a mais que a da comunidade local.

Além disso, com base nas observações juntamente nas análises das atas, não constam nos registros o tempo de duração das reuniões, a palavra dos membros e suas ponderações em cada pauta proposta, os regimes de votação e o cômputo de votos a favor e contra as deliberações e encaminhamentos, bem como as abstenções. Isso denota que a condução das reuniões, o registro das atas não segue o protocolo convencional de 
reuniões de colegiados. Saliente-se que esta dinâmica não está prevista em nenhuma legislação municipal, de modo que são os membros que acabam por estabelecer um protocolo de funcionamento das reuniões. Extraímos da ata de uma escola analisada um exemplo a esse respeito, sobretudo trazida para a reunião colegiada a partir de uma deliberação já preestabelecida pela direção escolar: “[...]sobre as necessidades da escola e a importância de campanhas que contribuam com as receitas da APM, nesse sentido, o grupo decidiu pela continuidade das 'Manhãs e Tardes de Pratos' a serem realizadas trimestralmente nas reuniões de pais e mestres [...] (ATA 74/2016, de 02/06/2016).

Conforme o trecho exposto, consideramos o segundo apontamento no que se referem às ações estabelecidas nos órgãos colegiados, isto é, as mobilizações estabelecidas pela equipe gestora com relação às campanhas para a captação de recursos financeiros, principalmente, envolvendo a participação ativa da comunidade escolar.

Nas análises das atas constatamos uma série de registros a respeito de deliberações referentes a organização de festas comemorativas e de eventos programados no calendário escolar e atribuído pelo conselho a importância expressiva da comunidade local neste momento. A participação cidadã da comunidade é associada à uma colaboração nas festas de arrecadação de fundos - eleitas como mecanismo privilegiado para a obtenção de fontes alternativas de financiamento em relação às oficiais, tais como FUNDEB e PPDE para a manutenção do ambiente escolar, conforme expresso na ata de uma das escolas analisadas: “[...] 4) Foi decidido que na festa junina que acontecerá dia 10/06 na escola serão vendidos pastéis de queijo e carne ao preço de $\mathrm{R}$ \$ 2,50 cada e refrigerantes no copo de $200 \mathrm{ml}$ ao preço de $\mathrm{R}$ \$ 1,00. Também serão vendidos doces (terceirizados) em que uma porcentagem fica para a APM da escola [...]” (ATA [?]/2016, de 23/05/2016).

Ressalta-se não só a presença dos membros da Associação de Pais e Mestres (APM), como também a sua importância nas reuniões dos conselhos escolares: em cinco escolas sendo observado que os representantes da APM de cada segmento são os mesmos dos conselhos escolares; evidenciamos nas pautas e nos informes referentes a parte financeira de todas as escolas, a caracterização da APM como um órgão interno da escola para captação de recursos, fomentando o processo de doações voluntárias da comunidade escolar, assim como na promoção de eventos culturais que envolva a escola e a sociedade (SÃO PAULO, 2010, p. 7).

Embora seja uma das atribuições da APM a promoção de eventos comemorativos, essa tarefa não é só incorporada pelos conselhos escolares como passa 
a ter um direcionamento, ou seja, a arrecadação de fundos conforme registrado nas atas das escolas enquanto atividade privilegiada, em detrimento de outras atividades previstas na legislação e que envolvem disputas políticas na escola. Tudo se passa como se o Conselho de escola fosse um órgão assessor da equipe gestora e não a instância máxima de deliberação de assuntos de gestão, políticas e outros aspectos para a escola, celebrando a já prevista na legislação municipal função tarefeira de administração burocrática e a resolução de problemas: “[...] a extrema importância do Conselho de Escola como órgão colegiado [...] como Instituição auxiliar e atuante como subsidiadora de processo de ensino-aprendizagem, como, por exemplo, materiais escolares diversos [...] bem como a manutenção básica de pequenos serviços do prédio escolar [...]"(ATA [?]/2016, de 09/05/2016).

Verificamos nas atas a recorrência de informes e deliberações envolvendo a parte financeira nas reuniões colegiadas, sobretudo a ênfase nos balancetes contábeis, a quantia das arrecadações obtidas e os gastos estabelecidos em sete atas analisadas.

As discussões de caráter pedagógico apareceram em apenas duas atas e se referiam a temas, tais como a doação de livros da escola para os alunos e o resultado da reunião de pais e mestres envolvendo a apresentação da proposta de trabalho dos professores para os pais, contudo, entendida nos documentos oficiais sob o caráter de informe do que uma proposta de pauta discutida nas reuniões.

Podemos constatar dos apontamentos levantados que há uma priorização da discussão sobre as finanças da escola em detrimento de outros aspectos da gestão democrática, tais como os pedagógicos e administrativos.

A partir do modus operandi dos Conselhos de Escola identificamos uma gestão escolar que se restringe à serviços burocráticos e contábeis, segundo um modelo empresarial e voltadas para a melhoria do ambiente físico escolar (SILVA; ALVES, 2012). Apesar de essas discussões serem relevantes ao funcionamento da escola, não são suficientes para a realização de uma gestão democrática da escola, na medida em que envolvem uma atuação conjunta dos profissionais da educação e da comunidade local sob a forma determinada.

Nossas constatações corroboram a ideia de que existe uma divisão do trabalho entre os membros dos conselhos, de modo que as formas de participação cidadã estabelecida vem orientando diferentes formas de atuação para os representantes da equipe escolar e para os da comunidade local: aos primeiros, estabelecidas e assumidas as tarefas relacionadas ao fomento, administração e gerência dos recursos obtidos para a 
manutenção da escola pública, segundo Paro (2005) ocorrendo um arranjo entre funcionários do Estado para elaboração das proposições e deliberações; aos últimos, delegas as tarefas de colaboração voluntária nas festas e outros eventos, reproduzido nos processos de arrecadação de doações e outras tarefas de cunho mais prático “[...] como cumpridores de regras sem formalmente questioná-las [...]" (JAPECANGA, 2000, 42).

Portanto, há também uma hierarquia na distribuição das responsabilidades entre os segmentos participantes do conselho de escola, o que acaba por corroer o potencial democrático dos órgãos colegiados na medida em que,

A participação mais efetiva da população nas atividades educacionais [...] parece não estar servindo satisfatoriamente a essa função devido ao seu caráter formalista e burocratizado [...] apesar de importante local de discussão e explicitação de conflitos, não tem logrado constituir um foro significativo de decisões, de modo a promover qualquer tipo de democratização das relações no interior da escola [...] (PARO, 2005, p. 45-46).

Processa-se uma dicotomização dos conselhos em quadros da escola e da comunidade escolar e estabelece-se uma hierarquia fundamentada no argumento de que os profissionais da escola são os que conhecem melhor os trâmites burocráticos. Com isso, dá-se a divisão de tarefas de modo que os gestores permaneçam concentrando tarefas de gestão e os membros oriundos da comunidade escolar assumam tarefas voluntaristas. Assim, esvazia-se os conselhos de qualquer possibilidade de uma discussão mais politizada, com disputas de linhas de ação, o que fragiliza a construção deste órgão escolar como uma instância de deliberação autônoma.

É esta, pois, a forma de gestão democrática possível sob a égide da estratégia político econômica neoliberal, à medida que há uma valorização da racionalização, da eficiência e da eficácia em detrimento dos longos e exaustivos debates políticos. A reprodução de relações burocráticas e hierarquizadas entre os segmentos do conselho nas reuniões, perpetua uma gestão autoritária dissimulada num órgão deliberativo colegiado - cuja paridade é apenas formal e no momento da escolha dos representantes - e a instância decisória é resgatada pela gerência no interior do próprio conselho e com a anuência da comunidade, quando presentes não disputa poder e submete-se às decisões, ademais, assume a postura voluntarista e colaboracionista. 


\section{Considerações finais}

A análise sobre o princípio da gestão democrática da escola nos permitiu pensar a categoria mediação em meio às disputas políticas envolvendo a perpetuação da classe burguesa no poder político como indicativo do antagonismo histórico de classes, assim como as relações entre Estado e escola nos processos de conciliação de classes desenvolvidas no neoliberalismo.

A análise empírica dos Conselhos de Escola, depreende-se que, embora tenham representado um avanço em relação à gestão centralizada na figura do diretor, ainda não logrou êxito em proporcionar uma ampliação do direito democrático de a comunidade escolar gerir a escola coletiva e autonomamente. Não depende, porém, somente dos conselhos e dos gestores a edificação de um novo modelo de gestão efetivamente participativo, mas, de mudanças no próprio modelo de Estado para que se alivie a pressão pela eficácia, eficiência e racionalização das escolas que emana de instituições extraescolares avaliadoras da escola de fora para dentro, baseada em critérios empresariais.

Assim, ao mesmo tempo em que é desenvolvida a nova trajetória política e jurídica da sociedade civil no processo de gestão escolar com base na participação cidadã a partir da redemocratização do país, passam ser estabelecidos os processos de desconcentração de tarefas nas instituições públicas estatais (FONSECA, 2013; COSTA, 2013).

Destacamos de Nardi (2015) que as apostas quanto à participação social e cidadania são apresentadas e legitimadas nesse sentido a partir da enunciação de finalidades coletivas e numa atuação política mais direta da classe trabalhadora nos assuntos públicos. Contudo, isso se concretiza nos moldes da forma democrática representativa burguesa. Trata-se da produção de uma nova hegemonia política da classe burguesa no poder, ao ressignificar os conceitos de participação social e cidadania sob o discurso ideológico da democracia, pois, na medida em que é convertida uma ideia numa ação de massa, para tanto sendo necessário que as vontades com fins heterogêneos sejam fundamentadas na busca de um mesmo fim, de uma base comum e numa idêntica concepção de mundo (GRAMSCI, 1978).

Nesse sentido a forma democrática representativa burguesa passa a ser expressada como fruto de uma vontade coletiva e com vistas para uma maior justiça social - a igualdade de condições e uma maior liberdade de ação na sociedade de classes. A 
escola, por sua vez, torna-se fundamental neste processo à medida que está “[...] profundamente implicada com as transformações aqui referidas, também foi e continua sendo palco de tensões e desafios que atravessam a questão da democracia no país" (NARDI, 2015, p. 650).

A classe trabalhadora, tendo em vista o redimensionamento político sob a ordem democrática neoliberal, tem sido convocada a atuar de modo ativo nos processos decisórios educacionais e a partir dos Conselhos de Escola - a instância de maior deliberação política - assumindo aí uma atuação estratégica nas unidades escolares. De acordo com Paro (1991), os mecanismos de controle democrático do Estado exigem a presença formal dos usuários na gestão da escola, sendo mais importante, antes, a eficácia com que defende os seus direitos de cidadão, do que os saberes técnicos sobre a forma de administrar, os quais são exercidos pelos gestores profissionais da escola.

Nardi (2015, p. 650) aponta que as ações políticas e as medidas educacionais, por vezes, são estabelecidas com “[...] funções simbólicas de reforço à participação e à autonomia da escola, com o fim de produzir a legitimação do controle pelo centro [...]", isto é, com base numa participação tutelada pelo Estado burguês de forma estratégica no que se refere o financiamento da escola, verificado aí a importância da participação formal da classe trabalhadora nestas decisões.

Tendo como base a síntese sobre as nove escolas enquanto uma amostra empírica sobre a aplicabilidade da política pública nas legislações educacionais da cidade de Rio Claro, consideramos as condições estabelecidas institucionalmente nas políticas locais sobre a promoção da gestão democrática do ensino, principalmente esclarecendo as consequências sobre a centralização do diretor da escola na gestão escolar: convocado para implementar ações com vistas a produzir resultados sobre a eficiência na administração escolar, informando um determinado referencial de qualidade (NARDI, 2015).

Concordamos assim com Paro $(1991$; 1996) e Japecanga (2000, p. 43) de que o Estado, no processo de gestão escolar, reserva uma função fundamental para o diretor de escola, qual

seja, a de gerente que deve fazer de tudo para que a escola funcione tal e qual uma empresa capitalista. Não é preconizada mais a figura de um diretor escolar enquanto membro da classe trabalhadora, mas, o de diretor-gerente que o Estado projeta para o cumprimento da política pública em questão. 
Verificamos que a dimensão da participação social e da cidadania para a classe trabalhadora estabelecida pelas políticas de Estado neoliberal apresentam limites na prática da gestão escolar e decorrem de práticas autoritárias existentes no interior dos conselhos e que não são sequer questionadas. Ademais, sob a forma tutelada pelo Estado, os quadros profissionais e não profissionais da comunidade escolar passam a ser co-responsáveis diretos pelo desenvolvimento da gestão financeira da unidade escolar, tendo em vista a desconcentração de tarefas do Estado e a proposição de uma forma mais democrática de organização educacional.

\section{Referencias}

ADRIÃO, T.; CAMARGO, R. B. A gestão democrática na Constituição Federal de 1988. In.:___ (Org.). Gestão financiamento e direito à educação: análise da LDB e da Constituição Federal. São Paulo: Xamã, 2001.

BRASIL. Lei n ${ }^{\circ}$ 9.394, de 20 de dezembro de 1996. Estabelece as diretrizes e bases da educação nacional. Diário Oficial da República Federativa do Brasil, Brasília, DF, n. 248, p. 279, 23 dez. 1996, Seção 1.

BRESSER PEREIRA, L. C. A reforma do Estado nos anos 90: Lógica e mecanismos de controle. vol. 1. Brasília: Ministério da Administração Federal e Reforma do Estado, 1997.

COSTA, A. C. O regime de colaboração entre União, estados e municípios no financiamento da educação no Brasil. Revista Brasileira de Política e administração escolar, n. 1, p. 105-121, jan-abr. 2010. Disponível em: <http://www.seer.ufrgs.br/rbpae/article/view/19685>. Acesso em: 10 jul. 2016.

COSTA, A. C. As relações entre Estado e escola no neoliberalismo: a função social da escola no Estado mínimo e as novas orientações às políticas educacionais. Curitiba: Appris, 2013.

FALEIROS, V. P. A política social do Estado capitalista: as funções da previdência e da assistência sociais. São Paulo: Cortez, 1987.

FONSECA, D. C. Conselhos de controle social, conselho escolar e trabalho coletivo. In: LUIZ, M. C.; NASCENTE, R. M. M. (Org.) Conselho escolar e diversidade: por uma escola mais democrática. São Carlos: EdUFSCar, 2013.

GRAMSCI, A. Concepção dialética da história. Rio de Janeiro: Civilização Brasileira, 1978.

GRAMSCI, A. Maquiavel, a política e o Estado Moderno. Rio de Janeiro: Civilização Brasileira, 1980. 
HAYEK, F. A. O caminho da servidão. 6. ed. São Paulo: Instituto Ludwig von Mises Brasil, 2010.

JAPECANGA, A. P. A democratização das relações de trabalho na escola pública básica. In.: VIEITEZ, C. G.; DAL RI, N. M. (Org.). Organizações e democracia. Marília: UNESP-Marília-Publicações, 2000.

LUDWIG, A. C. W. Administração escolar, pesquisa e qualidade na educação. In.: FARIAS, A. M. (Org.). Gestão educacional. Secretaria Municipal de Educação. Rio Claro: Prefeitura Municipal de Rio Claro, 2009. p. 9-26.

MARX, K. O Capital. Coleção os economistas, vol. I. São Paulo: Nova Cultural, 1996.

MARX, K. Crítica da filosofia do direito de Hegel. 2. ed. revista. São Paulo: Boitempo, 2010.

NARDI, E. L. Itinerários da participação na gestão de escolas públicas de Educação Básica. Revista Brasileira de Política e Administração da Educação. n. 3, p. 649666, set.-dez. 2015. Disponível em: <http://www.seer.ufrgs.br/rbpae/article/view/59089>. Acesso em: 15 set. 2016.

PARO, V. H. Administração escolar: introdução crítica. 5. ed. São Paulo: Cortez, 1991.

PARO, V. H. Eleição de diretores: a escola pública experimenta a democracia. Campinas: Papirus,1996.

PARO, V. H. Gestão democrática da escola pública. 3. ed. São Paulo: Editora Ática, 2005.

RIO CLARO, Lei no 2. 081, de 31 de outubro de 1986. Dispõe sobre o Estatuto do Magistério Público do Município de Rio Claro e dá outras providências. Prefeitura Municipal de Rio Claro, Estado de São Paulo, 31 out. 1986. Disponível em: <http://rioclaro.linkway.net.br/pdfs/CODIGOLEI_3774.pdf>. Acesso em: 10 jun. 2016.

Lei no 3.031, de 25 de março de 1999. Dá nova redação aos artigos de nº 123 a 127, e nova denominação ao Título XIV, DO COLEGIADO, da Lei no 2081 de 31 de outubro de 1986, Estatuto do Magistério Público Municipal de Rio Claro e dá outras providências. Prefeitura Municipal de Rio Claro, Estado de São Paulo, 25 mar. 1999. Disponível em: <http://rioclaro.linkway.net.br/pdfs/CODIGOLEI_6274.pdf〉. Acesso em: 10 jun. 2016.

Lei $\mathbf{n}^{\mathbf{0}}$ 4.247, de 30 de setembro de 2011. Cria e regulamenta os Conselhos de Escola nos estabelecimentos de ensino da Rede Municipal de Rio Claro e dá outras providências. Prefeitura Municipal de Rio Claro, Estado de São Paulo, 30 set. 2011. Disponível

em: <http://www.educacaorc.com.br/media/biblioteca/7000787/Lei\%204247_2011_Conselh o\%20de\%20Escola.pdf>. Acesso em: 10 jun. 2016.

SÃO PAULO. Lei complementar $\mathbf{n}^{\circ}$ 444, de 27 de dezembro de 1985. Dispõe sobre o 
Estatuto do Magistério Paulista e dá providências correlatas. Diário Oficial do Estado de

São Paulo, SP, 28 dez. 1985. Disponível em: <http://www.al.sp.gov.br/repositorio/legislacao/lei.complementar/1985/lei.complementa r-444-27.12.1985.html>. Acesso em: 05 mar. 2016.

Manual de utilização dos recursos do convênio FDE-APM. Secretaria da Educação do Estado de São Paulo, 2010. Disponível em: http://file.fde.sp.gov.br/portalfde/Arquivo/DocRedeEnsino/manual_apm.pdf. Acesso em: 06 ago. 2016.

SECRETARIA MUNICIPAL DE EDUCAÇÃO. Ata 74 do Conselho de Escola, de 02 de junho de 2016. Escola Municipal de Educação Fundamental Profa. Jovelina Moratelli. Rio Claro. 2016 (mimeogr.).

Ata da reunião do Conselho de Escola, de 23 de maio de 2016. Escola Municipal de Educação Fundamental Prof. Victorino Machado. Rio Claro. 2016. (mimeogr.).

Ata da reunião do Conselho de Escola, de 09 de maio de 2016. Escola Municipal de Educação Fundamental Monsenhor Martins. Rio Claro. 2016. (mimeogr.).

SILVA, L. G. A.; ALVES, M. F. Gerencialismo na escola pública: contradições e desafios concernentes à gestão, à autonomia e à organização do trabalho escolar. Revista Brasileira de Administração e Política Educacional. n. 3, p. 665-679, set.dez. 2012. Disponível em: <http://seer.ufrgs.br/rbpae/article/view/39833/25388>. Acesso em: 15 set. 2016.

SILVEIRA, A. A. D.; ADRIÃO, T. Conselho de escola: instrumento de democratização da gestão escolar. In.: FARIAS, A. M. (Org.). Gestão educacional. Secretaria Municipal de Educação. Rio Claro: Prefeitura Municipal de Rio Claro, 2009.

\section{Como referenciar este artigo}

ROCHA, Jefferson Alves da.; COSTA, Áurea de Carvalho. O descompasso entre a legislação que regula a gestão democrática da escola e o funcionamento dos conselhos de escola. Revista on line de Política e Gestão Educacional, Araraquara, v.20, n.2, p. 202-222, 2016. Disponível em: 〈http://dx.doi.org/10.22633/rpge.v20.n2.9460>. ISSN: $1519-9029$.

Submetido em: ago/2016

Aprovado em: nov/2016 